\title{
Standardisation of ophthalmic qualifications in Europe
}

Europe, in its true geographical sense of a continent extending from the Atlantic to the Urals, has such a variety of languages and cultures as to defy description and make one only marvel at the success of the USA in unifying a similarly vast continent. This article is confined to Europe of the European Union (EU) and the prospective members of the EU-that is, the northern European countries; Austria, Belgium, Denmark, Finland, France, Germany, the Netherlands, Ireland, Luxembourg, Sweden, and UK, and the southern European countries; Greece, Italy, Portugal, and Spain. Norway and Switzerland, although not members of the EU, have been recognised as members of the UEMS and send a delegate to many organisations. This large and disparate group will require major concessions among ourselves to produce a truly European state. Medicine is in many ways one of the simpler areas of activity to standardise, as there is a fairly broad consensus as to what a trained specialist should be. Up to now each country has controlled its specialist training in a completely individual way. The European Board of Ophthalmology (EBO) has been established with the aim of addressing this specific issue and developing a 'standard' examination for trainee ophthalmic specialists (see below).

Basically there are three types of controlling authority. Some countries work through university departments controlled by a professor and Germany is at the forefront of this system. In addition, physician councils of the 16 federal states of Germany determine which non-university departments are allowed to train doctors. Other countries organise and control specialist training through elected colleges of ophthalmology of which the UK is the prime example. The third mechanism utilises an official state body and, perhaps, France would be the leader here.

Each system has its own merits and disadvantages. Professorial control, to be satisfactory, requires a very high standard of commitment and enthusiasm from one individual and may therefore be subject to great variation, one unit being world class and another leaving much to be desired. The personal aspects of this system are probably its biggest weakness, while tradition and dedication are major strengths.

The college system operates in the UK and in Ireland and is the system which seems to have most support. The college is an academic body of all suitably and fully trained ophthalmologists who become members or more usually fellows of the college by undergoing a recognised training and then passing a qualifying examination. All fellows, be they professors or more humble practitioners of their skills, are equal in the eyes of the college. All affairs relating to the professional life of the practitioner are the affairs of the college. Subcommittees are established to inspect training units so that they conform to standards set by the college. Residents in training are interviewed and professional examinations are organised and conducted by the college. Annual scientific meetings, teaching courses, and research symposia are all part of the brief of a college.

The state institutes system removes much of the control of medical affairs from the medical establishment which may cause some resentment within the profession. However, the general public may prefer such a system as, in theory, it is removed from bias and the profession's vested interests. State control has the disadvantage of being cumbersome and legalistic. It is very difficult to alter established regulations.

In European ophthalmology, there are several major bodies dealing with a variety of ophthalmic affairs and also many subspecialty groups. These include the following.

\section{The Union Européene des Médecins Spécialistes (UEMS)}

This body was established a year after the signing of the Treaty of Rome. It is the only body recognised by the Commission of the EU in an advisory capacity Each country of the EU elects two members but each country only has one vote. The management committee of the UEMS recognises 30 specialist groups, one of which is ophthalmology. These groups act as advisory bodies to this management committee.

The specialist sections meet at least annually with two representatives from each country. They consider subjects referred to them by the comite permanente and also any matters relating to ophthalmology that the members themselves care to raise. Up to now it has had mainly a political role although everything in the directives and the ACMTs (Advisory Committee for Medical Training) have been drawn up in close cooperation with the UEMS, notably the very important recommendations of 1983.

\section{The Societas Ophthalmologica Europaea (SOE)}

This society is the major European scientific group conducting the European Congress and is the largest scientific society. However, it is a society transcending the boundaries of the EU and encompassing the geographical entity of Europe and thus has no statutory importance in deciding the affairs of the EU countries.

\section{The European University Professors of Ophthalmology (EUPO)}

All professors who are heads of academic departments in countries of the EU are eligible for membership, other countries send observers. This body has its primary interest in teaching and research and does not concern itself with political matters. It has very successfully established a European course for residents in training which is run annually and has been attended by up to 900 residents at each course. An optional MCQ examination has been conducted as the first glimmer of a European Board examination. To date the course has been conducted on a modular basis over a four year cycle.

EUPO has been a most successful venture bringing together professors from all the EU countries and their residents. It is now well established and will have a major role in European ophthalmology in the future. Fruitful cooperation has been established between EUPO and the UEMS. EUPO does not have any statutory authority and therefore acts as an advisory body only.

\section{Joint European Research Meetings in Ophthalmology and Vision (JERMOV)}

This group has been set up to coordinate European ophthalmology research groups particularly the AER 
(Association for Eye Research) and ECORA (European Community Ophthalmic Research Association).

It is also hoped that the EUPO residents' course can be held as frequently as possible at this meeting. The JERMOV meeting may also prove to be a useful venue for the EBO examination.

\section{Association for Eye Research (AER)}

This body holds annual basic science and clinical research group meetings and is successfully acting as a forum to pull together researchers from all European countries, including non-EU countries, with similar interests, again with no statutory status.

\section{The European Community Ophthalmic Research Association (ECORA)}

This research group was set up by EUPO to pull together all ophthalmic research workers, medical, non-medical basic sciences, and associated researchers.

\section{The European Ophthalmic Pathology Society} Founded in 1962, it consists of 40 elected members who meet annually in different European countries.

\section{The European Neuro-ophthalmological Society}

\section{The European Cataract and Refractive Surgery Society}

\section{The subspecialty groups}

The subspecialty groups such as the European Glaucoma Society, The European Contact Lens Society of Ophthalmologists, the European Club for Ocular Fine Structure, the Ophthalmic Oncology Group, and the European Strabismus Association are concerned only with the appropriate subspecialty but have all served greatly to weld together the ophthalmologists of Europe into a corporate identity.

The suggestion has been made by EUPO and the SOE that all these groups have an umbrella organisation, the European Academy, similar to the American Academy.

The most important and pressing problem is to attempt to harmonise training standards, so that the idea of free movement of the ophthalmologists in the EU can be implemented, and thus to enhance the quality of eye care in the EU. This implies a recognition of standards of training and knowledge to at least a minimum level. Because it is the only statutory body, the UEMS has recommended to all the specialist groups it recognises that they each establish a European Board with the aim of setting up a European examination and inspection of training units. Members should be leading representatives of their respective specialties. The draft statutes state that the primary objective is to guarantee the highest standards of care in the field of the specialty concerned in the countries of the EU, by ensuring that the training of the specialist doctor is raised to the highest possible level. This can be achieved by establishing or developing:

(a) standards required for the training of their specialists and the maintenance of these standards;

(b) proposals for the quality of training and for the syllabus for their specialty; (c) procedures to activate the free movement of specialist doctors throughout the EU;

(d) criteria to which the training centres for their specialty should conform;

(e) responsibility for assessing the content and quality of training in the different countries of the EU;

(f) facilitation of the exchange of their specialist trainees between training centres of the various countries of the $\mathrm{EU}$, to ensure a better harmonisation and quality of training; and

(g) a system for 'recognition of quality control' in their specialty - that is, the 'European Board Qualification'.

In summary, as applied to ophthalmology, the board will define appropriate standards for a training unit, inspect any units that apply for training status, and then, when a resident has completed four years in such a unit, examine the candidate. Successful candidates will now have a European Board Certificate.

The European Board will not conflict with national bodies who will still continue to control their own affairs. Hopefully, it will act as a major influence for the good of ophthalmology in Europe and will be given the wholehearted support of the individual national organisations.

The European Board of Ophthalmology (EBO) has now been established and it held its first council meeting in London on 31 October 1992. At this meeting elected representatives of all the EU countries except Portugal met and elected representatives.

The first president was Professor August Deutman followed by Professor Jean Jacques De Laey and, more recently, Professor Gottfried O H Naumann.

The following committees have been established:

Executive

Education

Residency review

Residency exchange

Manpower

Finance

All these committees are working actively and the first examination of the EBO was held at the congress of the SOE in Milan in June 1995. The format was an MCQ paper followed by an oral examination. The successful candidates were awarded a diploma, the EBOD.

The second examination was held in Paris in May 1996 and preparations are in hand for the third examination which will also be held in Paris in May 1997. In addition to the examination there has been general agreement that the format of the examination is working satisfactorily and will not be changed in the immediate future. The residency review committee has commenced inspection and the first unit to meet EBO standards (appropriately Maastricht) has been visited and approved.

A grandfather clause of diploma ad eundem is being prepared and will be offered to all ophthalmologists meeting the requirements of the EBO and approved by their own national authorities. Details of this offer will be published in due course in national journals.

PETER EUSTACE Secretary General

European Board of Ophthalmology,

Institute of Ophthalmology,

University College Dublin,

60 Eccles Street, Dublin 7, Ireland 